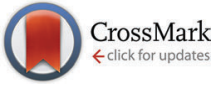

Cite this: J. Mater. Chem. C, 2016, 4, 11499

Received 19th August 2016, Accepted 18th November 2016

DOI: $10.1039 / \mathrm{c} 6 \mathrm{tc} 03585 \mathrm{j}$

www.rsc.org/MaterialsC

\section{Cool to warm white light emission from hybrid inorganic/organic light-emitting diodes}

\author{
Elaine Taylor-Shaw, ${ }^{* a}$ Enrico Angioni, ${ }^{b}$ Neil J. Findlay, ${ }^{b}$ Benjamin Breig, ${ }^{b}$ \\ Anto R. Inigo, ${ }^{\mathrm{b}}$ Jochen Bruckbauer, ${ }^{a}$ David J. Wallis, ${ }^{c d}$ Peter J. Skabara*b and \\ Robert W. Martin*a
}

\begin{abstract}
The synthesis and characterisation of two novel organic down-converting molecules is disclosed, together with their performance as functional colour-converters in combination with inorganic blue light-emitting diodes (LEDs). Each molecule contains two fluorene-triphenylamine arms, connected to either a benzothiadiazole or bisbenzothiadiazole core. These molecules have been selected on the basis that they are free from absorption bands in the green region of the visible spectrum to maximise their performance and offer improvements compared with previous BODIPY-containing analogues. The inorganic InGaN/GaN LED emits at $444 \mathrm{~nm}$, overlying the absorption of each of the organic molecules. The combination of the blue (inorganic) and yellow (organic) emission is shown to produce reasonable quality, white light-emitting hybrid devices for both down-converter molecules. Cool to warm white light is achieved for both molecules by increasing the concentration. An optimum colour rendering index (CRI) value of 66 is obtained for the mono-benzothiadiazole molecule. Also a high blue-to-white efficacy (defined as white luminous flux (lm)/blue radiant flux (W)) of $368 \mathrm{Im} \mathrm{W}^{-1}$ is achieved, superseding the current phosphor converters of 200-300 $\mathrm{lm} \mathrm{W}^{-1}$. A comparison of these down-converting molecules to the older generation BODIPY-containing molecules is also provided.
\end{abstract}

\section{Introduction}

Traditional lighting sources, such as incandescent and fluorescent bulbs, have been the dominant technology for domestic and commercial lighting worldwide despite suffering from low efficiencies and potentially toxic components. ${ }^{1}$ Solid-state lighting (SSL), using well-established and well-understood inorganic light-emitting diodes (LEDs) with light-converting phosphor coatings, are increasingly attractive replacements to traditional lighting technologies owing to their increased efficiency, long lifetime, improved light quality and low maintenance. They also offer the potential for application in intelligent lighting systems. ${ }^{2}$ Although organic light-emitting diodes (OLEDs) can offer significant advantages such as low-cost manufacturing and flexibility, their use as white light sources is limited by their overall lower efficiency compared with inorganic LEDs. An alternative platform is hybrid inorganic/organic architectures that aim to combine the benefits of both lighting methods;

\footnotetext{
${ }^{a}$ Department of Physics, SUPA, University of Strathclyde, Glasgow, G4 ONG, UK. E-mail: jochen.bruckbauer@strath.ac.uk

${ }^{b}$ WestCHEM, Department of Pure and Applied Chemistry, University of Strathclyde, Glasgow, G1 $1 X L$, UK

${ }^{c}$ Plessey Semiconductors Ltd, Roborough, Plymouth, PL6 7BQ, UK

${ }^{d}$ Department of Materials Science and Metallurgy, University of Cambridge,

27 Charles Babbage Road, Cambridge, CB3 OFS, UK
}

a blue, inorganic LED is coated with an organic, emissive downconverting layer. ${ }^{3-5}$ Crucially, the absorption band of the organic material must closely align with the emission band of the inorganic LED to be used as an efficient energy down-converter for white light generation. Some of the photons emitted from the blue LED excite the organic material producing yellow light, and the combination of the two creates white light. Blue inorganic LEDs based on III-nitride alloys are the material of choice and were recognised with the award of the Nobel Prize for Physics in $2014 .^{6}$ These materials can emit light from the ultra-violet (UV) region through the visible and to the infra-red. ${ }^{7}$ To produce highly efficient blue-emitting LEDs a series of thin InGaN layers are grown between several GaN layers creating a multi-quantum well structure, aiding carrier confinement and increased radiative recombination. Utilising hybrid inorganic/organic LED architectures offers the opportunity to combine the advantages of both technologies; the well-understood and high-performing electronic properties of inorganic LEDs with the broad, tunable emission of organic semiconducting materials. ${ }^{8-10}$ An additional advantage is the application of organic materials in place of phosphors in hybrid LEDs, lessening the industry dependence on expensive rare-earth raw materials as demand for solid-state lighting increases. ${ }^{11}$ The high speed of response of organic materials compared with existing phosphors offers additional advantages for applications such as visible light communications. ${ }^{12-14}$ 

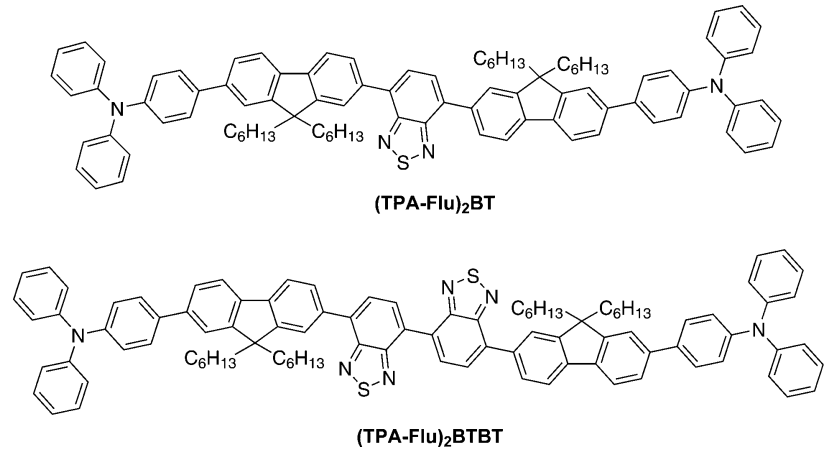

Fig. 1 The structures of (TPA-Flu $)_{2}$ BT and (TPA-Flu $)_{2}$ BTBT, respectively.

Over recent years we have reported our initial results in synthesising and deploying organic molecules as down-converting layers on top of inorganic InGaN LEDs. Although the first generation materials were incapable of absorbing blue light, they functioned as effective down-conversion layers for UV light resulting in yellow-emitting hybrid LEDs. ${ }^{15}$ More recently we disclosed a BODIPY-containing molecule that was capable of absorbing blue light and converting it into yellow, providing our first white hybrid inorganic/organic LED. ${ }^{16,17}$ Although the resulting device performed well with respectable commission internationale de l'éclairage (CIE) coordinates $(0.34,0.31)$, the device was far from ideal due to the lack of green emission from the BODIPY units. Also, self-absorption of the molecule contributed to the reduction of emission in the green region of the spectrum. Green emission is essential for improving the luminous efficacy of a white light-emitting device due to the peak of the human eye response at $555 \mathrm{~nm}$ in the green region of the visible spectrum. ${ }^{18}$ Also, the increased spectral width of the green-emitting region is seen to achieve a high colour rendering index (CRI) value while maintaining high luminous efficacy for simulated multi-LED emitters. ${ }^{19}$

In this work, we aim to improve this through the synthesis of a next generation of down-converter material that utilises either an electron-deficient 2,1,3-benzothiadiazole (BT) core, or the corresponding dimer, in tandem with fluorene and triphenylamine donor arms (Fig. 1). (TPA-Flu) $)_{2}$ BT and (TPA-Flu) ${ }_{2}$ BTBT have been studied as the down-conversion layer in hybrid inorganic/organic LEDs and can produce good quality light emission from cool to warm white. The smaller, better performing, monobenzothiadiazole-containing molecule ((TPA-Flu $\left.)_{2} \mathbf{B T}\right)$ demonstrates reasonable colour rendering quality $(60<$ CRI $<70)$ and a high blue-to-white efficacy of $368 \mathrm{~lm} \mathrm{~W}^{-1}$.

\section{Synthesis}

Both (TPA-Flu) ${ }_{2}$ BT and (TPA-Flu) $)_{2}$ BTBT follow a similar synthetic pathway. For the mono-benzothiadiazole analogue (TPA-Flu) $)_{2} \mathbf{B T}$, the commercially available 4,7-dibromo-2,1,3-benzothiadiazole core (1) was coupled to the substituted fluorene reagent A (Scheme 1) via a Suzuki-Miyaura coupling resulting in the extended molecule compound 2. To allow further reaction,

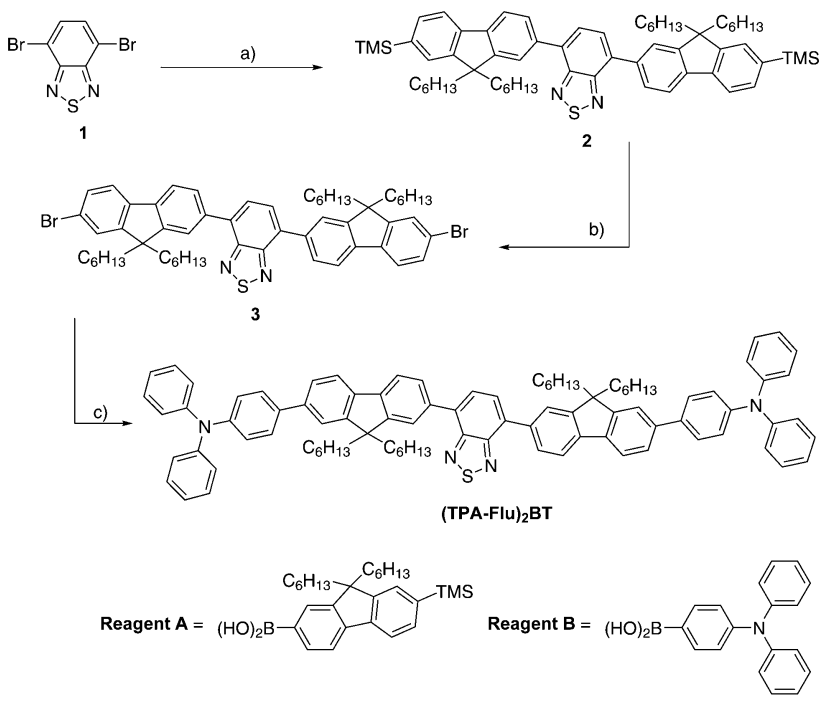

Scheme 1 The synthesis of (TPA-Flu) $)_{2} \mathrm{BT}$; (a) reagent $\mathrm{A}, \mathrm{Pd}\left(\mathrm{PPh}_{3}\right)_{4}, \mathrm{Ba}(\mathrm{OH})_{2}$. $\mathrm{H}_{2} \mathrm{O}$, THF/ $\mathrm{H}_{2} \mathrm{O}$ (10 : 1), 40 h, reflux, $\mathrm{Ar}, 82 \%$; (b) $\mathrm{Br}_{2}, \mathrm{NaOAc}, \mathrm{THF}, \mathrm{Ar}, \mathrm{O}^{\circ} \mathrm{C}$ - r.t., $24 \mathrm{~h}, 97 \%$; (c) 4-(diphenylamino)phenyl boronic acid (reagent $\mathrm{B}), \mathrm{Pd}\left(\mathrm{PPh}_{3}\right)_{4}$, $\mathrm{Ba}(\mathrm{OH})_{2} \cdot \mathrm{H}_{2} \mathrm{O}, \mathrm{THF} / \mathrm{H}_{2} \mathrm{O}(10: 1), 48 \mathrm{~h}$, reflux, $\mathrm{Ar}, 78 \%$.

the peripheral trimethylsilyl groups were brominated under mild conditions in high yield, affording the key intermediate compound 3. Finally, a second Suzuki-Miyaura coupling between compound 3 and 4-(diphenylamino)phenyl boronic acid (reagent B) afforded the mono-benzothiadiazole containing (TPA-Flu) $)_{2}$ BT in good yield (78\%).

For the larger analogue (TPA-Flu) $)_{2}$ BTBT, the bisbenzothiadiazole core was initially constructed. Starting with 4-bromo2,1,3-benzothiadiazole (compound 4), self-coupling using palladium(II) acetate afforded the bisbenzothiadiazole unit (compound 5), which was then iodinated in positions 7- and $7^{\prime}$ - to afford the functionalised bisbenzothiadiazole core compound 6 (Scheme 2). The synthesis then followed that of the smaller, mono-benzothiadiazole analogue: Suzuki-Miyaura coupling of compound 6 with reagent A to afford compound 7, followed by subsequent bromination of both peripheral trimethylsilyl (TMS) groups resulting in key intermediate 8. A second coupling reaction with reagent $\mathrm{B}$ afforded the bisbenzothiadiazole analogue (TPA-Flu $)_{2}$ BTBT in good yield (64\%). Both molecules were fully characterised by NMR, MALDI mass spectrometry and elemental analysis. Thermogravimetric analysis of both analogues revealed they were thermally stable up to temperatures greater than $400{ }^{\circ} \mathrm{C}$ (5\% mass loss at $435{ }^{\circ} \mathrm{C}$ and $418{ }^{\circ} \mathrm{C}$ for (TPA-Flu) $)_{2} \mathbf{B T}$ and (TPA-Flu) $)_{2}$ BTBT, respectively). Further details on the synthesis of the compounds can be found in the experimental section.

\section{Results and discussion}

\subsection{UV-Vis absorption and emission properties}

Applying molecules such as (TPA-Flu) ${ }_{2}$ BT and (TPA-Flu) ${ }_{2}$ BTBT as down-converting layers requires an understanding of their absorption and emission characteristics. Solution state UV-Vis absorption and photoluminescence measurements were performed 

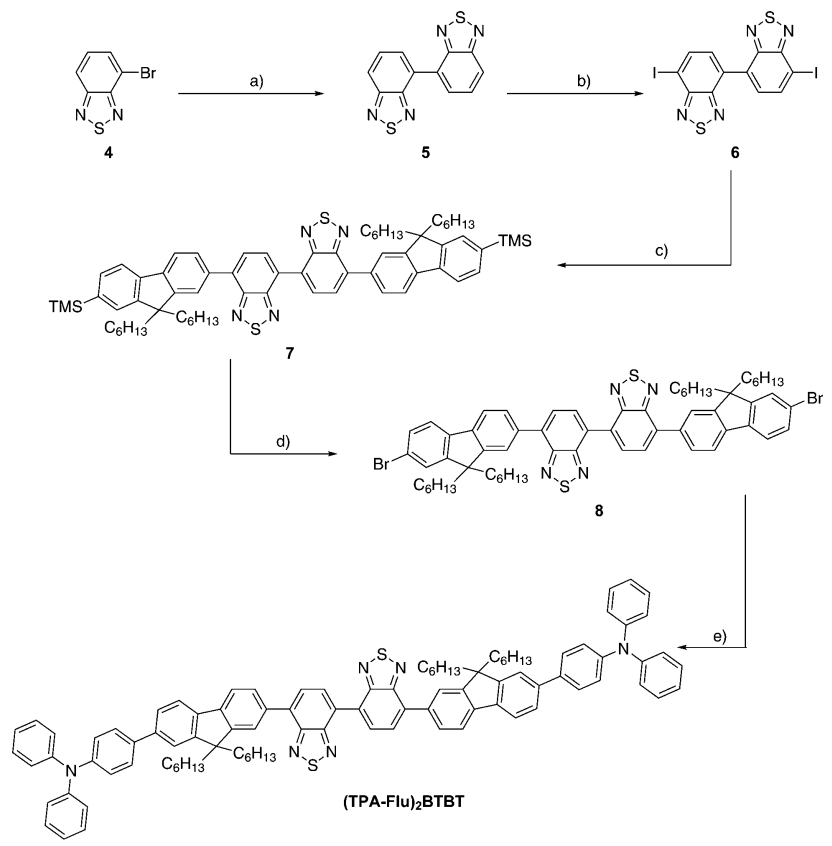

Scheme 2 The synthesis of (TPA-Flu $)_{2} \mathrm{BTBT}$; (a) $\mathrm{Pd}(\mathrm{OAC})_{2}, \mathrm{~K}_{2} \mathrm{CO}_{3}$ PEG4000, DMF, $120{ }^{\circ} \mathrm{C}, 20 \mathrm{~h}, \mathrm{~N}_{2}, 80 \%$; (b) (i) $\mathrm{Ag}_{2} \mathrm{SO}_{4}, \mathrm{H}_{2} \mathrm{SO}_{4}, \mathrm{I}_{2}, 3$ h, r.t. (ii) add to compound $5,110{ }^{\circ} \mathrm{C}, 1 \mathrm{~h}, 45 \%$; (c) reagent $\mathrm{A}, \mathrm{K}_{2} \mathrm{CO}_{3}, \mathrm{Pd}\left(\mathrm{PPh}_{3}\right)_{4}$, toluene, $120{ }^{\circ} \mathrm{C}, 70 \mathrm{~h}, \mathrm{Ar}, 62 \%$; (d) $\mathrm{Br}_{2}, \mathrm{NaOAc}, \mathrm{THF}, \mathrm{Ar}, 0{ }^{\circ} \mathrm{C}-\mathrm{r}$.t., $20 \mathrm{~h}$, 90\%; (e) 4-(diphenylamino)phenyl boronic acid (reagent $\mathrm{B}$ ), $\mathrm{Pd}\left(\mathrm{PPh}_{3}\right)_{4}$, $\mathrm{Ba}(\mathrm{OH})_{2} \cdot \mathrm{H}_{2} \mathrm{O}, \mathrm{Bu}_{4} \mathrm{NBr}, \mathrm{THF} / \mathrm{H}_{2} \mathrm{O}(9: 2), 44 \mathrm{~h}$, reflux, $\mathrm{Ar}, 64 \%$.

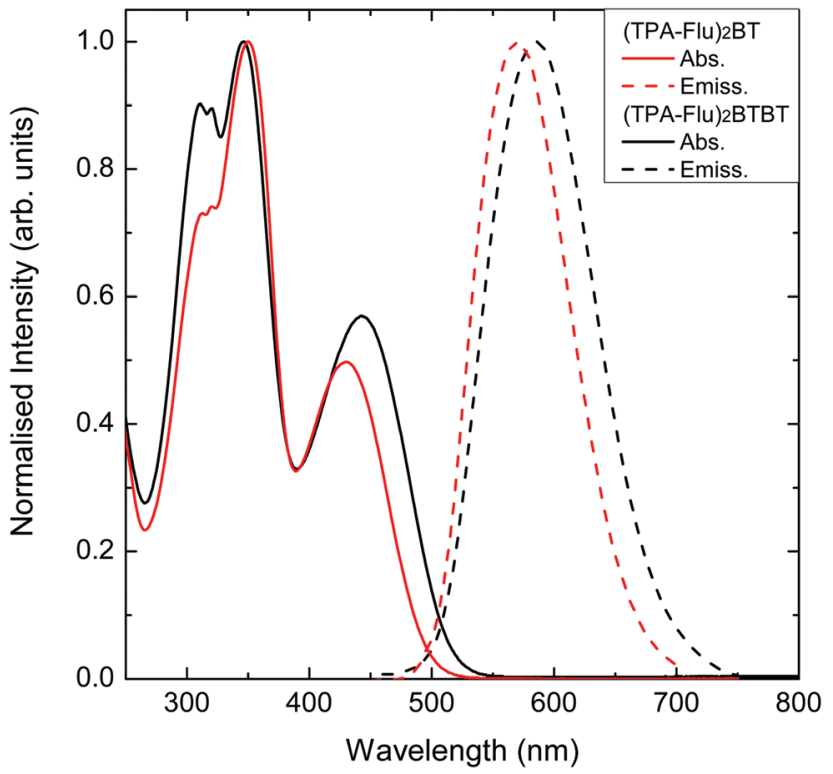

Fig. 2 Normalised UV-Vis absorption $\left(10^{-5} \mathrm{M}\right)$ and emission $\left(10^{-6} \mathrm{M}\right)$ spectra of (TPA-Flu) ${ }_{2}$ BT and (TPA-Flu) ${ }_{2}$ BTBT measured in dichloromethane dilute solution.

on dilute solutions in dichloromethane. The spectra are shown in Fig. 2. (TPA-Flu) ${ }_{2}$ BT exhibits two absorption peaks at $345 \mathrm{~nm}$ and $430 \mathrm{~nm}$ that likely correspond to $\pi-\pi^{*}$ and intermolecular charge transfer (ICT) bands, respectively. The introduction of the 2nd BT unit in (TPA-Flu) $)_{2}$ BTBT afforded a red-shift of the ICT band to
$443 \mathrm{~nm}$ but did not greatly affect the $\pi-\pi^{*}$ transition (343 nm). The emission characteristics of both compounds indicated that they were each suitable candidates for down-conversion of blue light. When excited at the wavelength corresponding to the ICT band (430 and $443 \mathrm{~nm}$ for (TPA-Flu) ${ }_{2}$ BT and (TPA-Flu) ${ }_{2}$ BTBT, respectively), emission at $570 \mathrm{~nm}$ for (TPA-Flu) ${ }_{2} \mathbf{B T}$ and $584 \mathrm{~nm}$ for (TPA-Flu) ${ }_{2}$ BTBT was recorded. Once again, the addition of the additional BT unit in (TPA-Flu) ${ }_{2}$ BTBT has afforded a red-shift in the emission properties compared with the mono-benzothiadiazole molecule. The photoluminescence quantum yields (PLQY) for (TPA-Flu) $)_{\mathbf{2}}$ BT and (TPA-Flu) ${ }_{2} \mathbf{B T B T}$ in encapsulated material were measured as $61 \%$ and $17 \%$ respectively, when excited at $444 \mathrm{~nm}$.

\subsection{Device properties}

The object of these organic wavelength converters is to generate white light from the combination of the blue emission from the inorganic LED with the emission from the organic colour converter. Images of the hybrid device, with the organic downconverter deposited on top of the inorganic LED, are shown in Fig. 3 with and without applied current. To assess whether white light is achieved the chromaticity coordinates of (TPA-Flu) ${ }_{2} \mathbf{B T}$ and (TPA-Flu) $)_{2}$ BTBT have been investigated as a function of concentration. The concentration is defined as the weight per volume $(\mathrm{w} / \mathrm{v})$ in the host matrix. The chromaticity coordinates are calculated from a spectrum, in this case an electroluminescence (EL) spectrum taken in an integrating sphere with each hybrid device driven at $25 \mathrm{~mA}$. The blue LEDs used in the hybrid devices are the same as those used in our previous publication and are identical in all cases, with only the converter changing. ${ }^{16}$ Fig. 4 illustrates the evolution of the chromaticity coordinates with concentration on a CIE 1931 diagram for both compounds, starting in the blue region and ending in the yellow/green region. (TPA-Flu) $)_{2}$ BT evolves from $0.05 \%$ to $2 \%$ concentration and (TPA-Flu) ${ }_{2}$ BTBT from $0.5 \%$ to $2 \%$. Both compounds lie near the desired region of the Planckian locus and cut through the centre of the diagram where white light is located. This implies that by varying the concentrations of each compound light emission of any colour can be generated along their relevant coordinate trajectory. The star symbols in Fig. 4 represent the chromaticity co-ordinates generated from the emission spectra of (TPA-Flu) $)_{2}$ BT and (TPA-Flu) ${ }_{2}$ BTBT in solution, shown in Fig. 2, without the blue InGaN LED. The reason for the shift towards the red region of the chromaticity diagram may be due to the differences between solution and solid state emission. The spectra
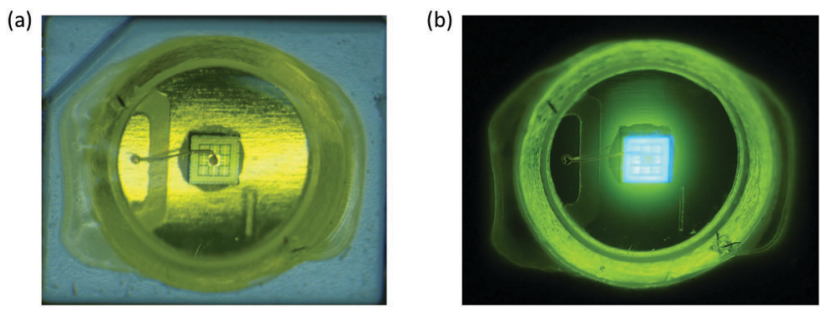

Fig. 3 Images of the hybrid device with organic converter deposited on the InGaN/GaN LED (a) turned off and (b) operating at $25 \mathrm{~mA}$. The size of the LED chip is $1 \mathrm{~mm}^{2}$. 


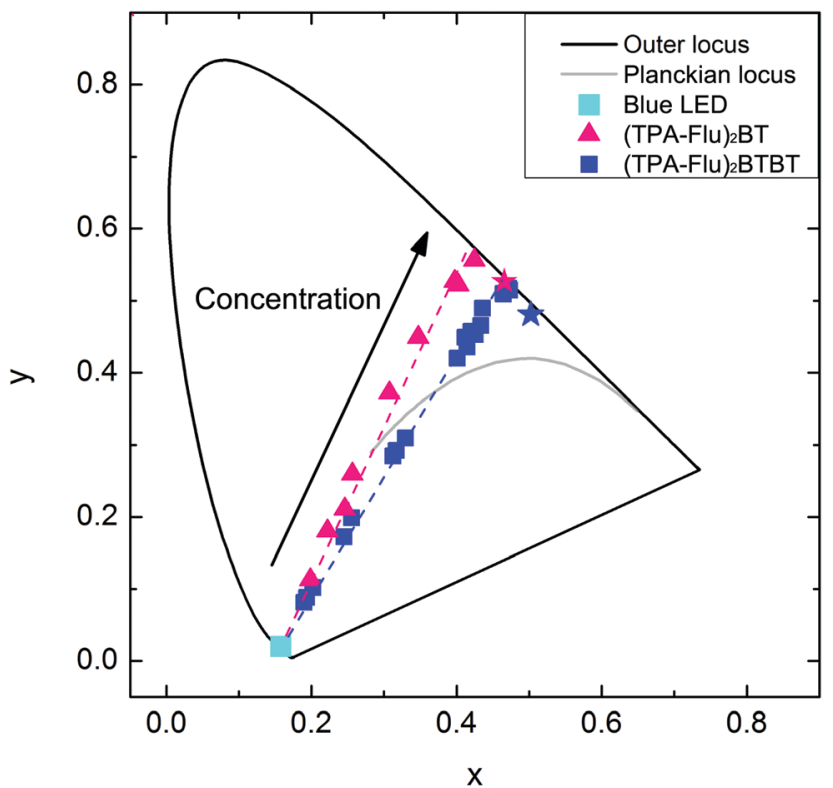

Fig. $41931 \mathrm{CIE}$ chromaticity diagram showing the evolution of coordinates with concentration for both (TPA-Flu) ${ }_{2}$ BT and (TPA-Flu) ${ }_{2}$ BTBT on a blue LED. Arrow indicates direction of increasing concentration for both converters. Stars represent the chromaticity coordinates of each of the converter materials without the LED.

of the converters alone were measured as a solution, and both are approximately $20 \mathrm{~nm}$ red-shifted with respect to the solid state converter emission of the hybrid LED presented in Fig. 5.

As an example, both cool and warm white EL spectra (taken at $25 \mathrm{~mA}$ ) that have chromaticity coordinates near the Planckian locus, but at the near extremes of the white colour region are presented in Fig. 5 for both converters. Cool and warm white

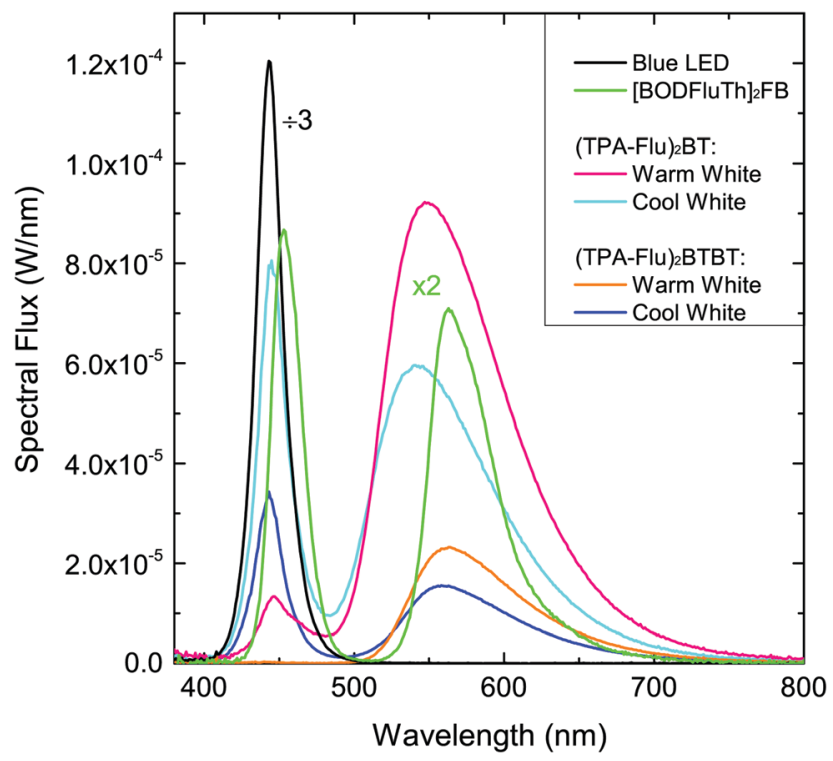

Fig. 5 EL spectra taken at $25 \mathrm{~mA}$ of (TPA-Flu) ${ }_{2}$ BT and (TPA-Flu) ${ }_{2}$ BTBT equivalent in CCT value to warm and cool white light. The blue LED spectrum used in the hybrid devices is shown (scaled down by 3 ) and for comparison a spectrum of [BODFluTh] ${ }_{2} \mathrm{FB}$ (scaled up by 2 ). light are identified by correlated colour temperatures (CCTs) near $10000 \mathrm{~K}$ and $2400 \mathrm{~K}$, respectively. The CCT value for a given spectrum is taken as the closest point from the chromaticity coordinates (calculated from the spectrum) to the Planckian locus. ${ }^{19}$ For both cool and warm white spectra, (TPA-Flu) ${ }_{2}$ BT is more than a factor of 2 higher in intensity than (TPA-Flu) $)_{2}$ BTBT. The radiant flux values reflect the greater spectral output of (TPA-Flu) ${ }_{2}$ BT compared with (TPA-Flu) ${ }_{2}$ BTBT; cool white (TPA-Flu) $)_{2} \mathbf{B T}$ is $8.6 \mathrm{~mW}$, warm white (TPA-Flu) $)_{2} \mathbf{B T}$ is $10.2 \mathrm{~mW}$, cool white (TPA-Flu) ${ }_{2}$ BTBT is $2.4 \mathrm{~mW}$ and warm white (TPA-Flu) $)_{2}$ BTBT is $2.3 \mathrm{~mW}$. As expected the organic emission peak increases with concentration for both converters. The warm white spectra presented in Fig. 5 highlight the greater intensity of the yellow emission from the converter compared to the blue. In both cases the blue peak is considerably reduced on going from cool to warm white light due to the high concentrations of converter material needed to achieve the lower CCT warm white light.

The spectra in Fig. 5 correspond to the circled chromaticity data points in the close-up of the Planckian locus in Fig. 6 . The points circled at the top of the figure correspond to the warm white spectra and the points further left correspond to the cool white spectra. The colour temperature isothermal lines are displayed to show the evolution from warm white $(2400 \mathrm{~K})$ to cool white $(10000 \mathrm{~K})$. The length of the isothermal lines are equivalent to a $D_{u v}$ value of \pm 0.04 , + above the Planckian locus and - below. The isothermal lines cut the Planckian locus perpendicularly on the 1960 CIE chromaticity diagram $((u, v)$ coordinate system), with the $D_{u v}$ as the distance between the Planckian locus and a point on that line. The evolution of cool to warm white light (increase in concentration) is highlighted by the dashed lines for each converter. (TPA-Flu) ${ }_{2}$ BTBT has a

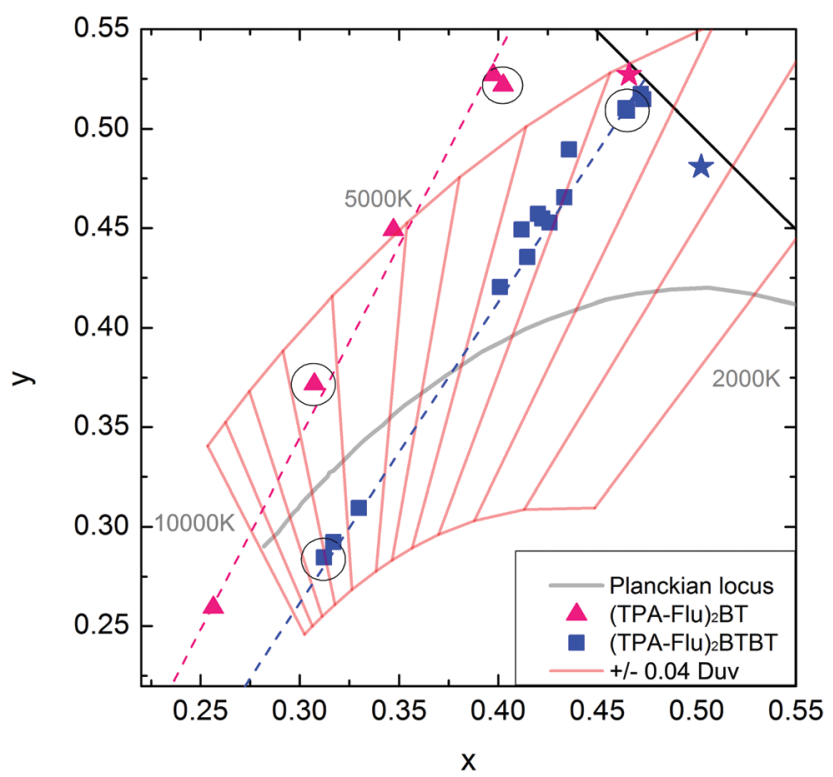

Fig. 6 Close-up of the Planckian locus with the isothermal lines (2000-10000 K) capped at $D_{u v}= \pm 0.04$. Dashed lines show the trajectory of chromaticity coordinates with concentration for each converter. Stars represent the chromaticity coordinates of each of the converter materials without the LED. 
greater range within the boxed $D_{u v}$ region suggesting that it is the better choice for use as a good quality white light source. However, when comparing other colorimetry values such as colour rendering index (CRI), (TPA-Flu) $)_{2} \mathbf{B T}$ has higher values than (TPA-Flu) ${ }_{2}$ BTBT. The CRI determines how well a white light source renders objects true in colour, with a perfect emitter having the highest possible value of $100{ }^{19}$ (TPA-Flu) ${ }_{2}$ BT has a CRI range of 51-66, while (TPA-Flu) ${ }_{2}$ BTBT has a range of 40-61 for the points displayed in Fig. 6 . The CRI value reduces as the concentration increases for the white light region, highlighting that reasonable rendering quality $(60<$ CRI $<70)$ cool white light can be achieved for both converters. Although this metric is the current standard and is widely used, it has deficiencies when used with solid-state lighting. ${ }^{19,20}$ A more appropriate metric for SSL is the colour quality scale (CQS) which includes the rendering of saturated colours in addition to the 8 Munsell colour shades used in CRI. ${ }^{21}$ Like CRI, the CQS maximum value of perfect colour rendering is 100 . (TPA-Flu) ${ }_{2}$ BT has a slightly higher CQS than CRI on average for the points lying within the cool to warm white regions $\left(\mathrm{CQS}_{\mathrm{avg}}=57\right)$, whereas (TPA-Flu $)_{2} \mathbf{B T B T}$ is lower $\left(\mathrm{CQS}_{\mathrm{avg}}=42\right)$. The CQS range for (TPA-Flu) $)_{2} \mathbf{B T}$ is comparable with the CRI at 51-66, whereas (TPA-Flu) $)_{2}$ BTBT differs considerably with a range of $3-55$. This suggests that (TPA-Flu) $)_{2} \mathbf{B T}$ is better at rendering saturated coloured objects than (TPA-Flu) $)_{2}$ BTBT. Also the lower CQS values of (TPA-Flu) ${ }_{2}$ BTBT would mean that the white light is no longer of reasonable quality with the highest CQS value being 55 .

In addition to the quality of light produced by a lightemitting device the efficacy is also important. The luminous efficacy $\left(\operatorname{lm~} \mathrm{W}^{-1}\right)$ is determined by the ratio of luminous flux $(\mathrm{lm})$ to the input electrical power (W). The luminous efficacy accounts for the response of the human eye which peaks at $683 \mathrm{~lm} \mathrm{~W}{ }^{-1}$ with a monochromatic light source of $555 \mathrm{~nm}$. For (TPA-Flu) ${ }_{2}$ BT the average luminous efficacy of the points in Fig. 6 is $41 \mathrm{~lm} \mathrm{~W}^{-1}$, while for (TPA-Flu) $_{2}$ BTBT the value is $10 \mathrm{~lm} \mathrm{~W}^{-1}$. This reflects the efficiency of the down-converting molecules as identical blue LEDs were used for all measurements (the blue LED spectrum is included in Fig. 5). The four times enhancement in luminous efficacy for (TPA-Flu) $)_{2} \mathbf{B T}$ compared with (TPA-Flu) $)_{\mathbf{2}} \mathbf{B T B T}$ arises mainly from differences in PLQY, (TPA-Flu) ${ }_{2}$ BT with $63 \%$ and (TPA-Flu) ${ }_{2}$ BTBT with $17 \%$. The radiant flux values follow the luminous efficacy differences by increasing approximately four times from (TPA-Flu) ${ }_{2}$ BTBT to (TPA-Flu) $)_{2}$ BT $(2.3 \mathrm{~mW}$ compared with $10.2 \mathrm{~mW})$. This is expected as the influence of the eye response function on the luminous flux values is minimal due to their similar emission spectra. An alternative standard used for efficiency is the ratio of the luminous flux ( $\mathrm{lm}$ ) of the combined blue LED with the converter to the radiant flux (W) of the blue LED alone. We define this as blue-to-white efficacy. The values for current phosphor-based LEDs are between 200-300 $\mathrm{lm} \mathrm{W}^{-1} \cdot{ }^{22}$ For (TPA-Flu) ${ }_{2}$ BTBT, the highest blue-to-white efficacy for the data points in Fig. 6, which lie in the cool to warm white region, is $116 \mathrm{~lm} \mathrm{~W}^{-1}$. (TPA-Flu) ${ }_{2}$ BT has a higher efficacy of $368 \mathrm{~lm} \mathrm{~W}^{-1}$; greater than current phosphor-based LEDs. If the excitation from the blue LED peak matches the absorption peak of the
(TPA-Flu) ${ }_{2}$ BT converter $(430 \mathrm{~nm})$ it may provide even higher blue-to-white efficacy as more blue photons would be absorbed and therefore converted, increasing the luminous flux. However, the shape of the resulting spectrum would change having an affect on the chromaticity co-ordinates and colour properties, possibly shifting it out of the desired white region.

Industry standards require the chromaticity points of a given light source to be within a tolerance of $\pm 0.006 D_{u v}$ from the Planckian locus as defined by the American National Standards Institute. ${ }^{23,24}$ This would restrict (TPA-Flu) $)_{2}$ BTBT to CCT values around $4000 \mathrm{~K}$ (warm white), and (TPA-Flu) ${ }_{2}$ BT to $\sim 10000 \mathrm{~K}$ (cool white). However, the better performing downconverter ((TPA-Flu $\left.)_{2} \mathbf{B T}\right)$ lies further from the Planckian locus, and outwith the industry standards, but has the higher radiant flux, CRI and efficacies for the cool to warm white range.

When comparing these down converters ((TPA-Flu) $)_{2} \mathbf{B T}$ and (TPA-Flu $)_{2}$ BTBT) to the earlier generation BODIPY-containing molecule ([BODFluTh $\left.]_{2} \mathbf{F B}\right)$ there are noticeable improvements. ${ }^{15-17}$ Earlier devices were limited by the low intensity in the green region, as a result of a combination of poor emission and selfabsorption in this region. The new materials show enhanced emission in the 490-520 $\mathrm{nm}$ region as shown in Fig. 5, which leads to notable increases in efficacy. The absorption and emission spectra (Fig. 2) of these newer molecules have less overlap compared with the older generation $[\text { BODFluTh }]_{2} \mathbf{F B}$ molecule, indicating there is reduced self-absorption on the lower wavelength side (i.e. green region) of the emission peak of the down-converter. This is evident in the luminous efficacy values with the [BODFluTh $]_{2} \mathbf{F B}$ molecule returning an optimum value of $13.6 \mathrm{~lm} \mathrm{~W}^{-1}$, and the average for (TPA-Flu) $)_{2} \mathbf{B T}$ and (TPA-Flu) ${ }_{2}$ BTBT being $41 \mathrm{~lm} \mathrm{~W}^{-1}$ and $10 \mathrm{~lm} \mathrm{~W}^{-1}$, respectively. For all down-converting molecules identical blue LEDs were used therefore the initial luminous efficacy is the same $\left(\approx 3.2 \mathrm{~lm} \mathrm{~W}^{-1}\right)$. The comparable luminous efficacy for (TPA-Flu $)_{2} \mathbf{B T B T}$ is due to the low PLQY of $17 \%$, whereas [BODFluTh $]_{2} \mathbf{F B}$ and (TPA-Flu) $)_{2} \mathbf{B T}$ have PLQY values of $63 \%$ and $61 \%$, respectively. Preliminary lifetime studies of the hybrid LEDs using (TPA-Flu) ${ }_{2} \mathbf{B T}$ and (TPA-Flu) $)_{2}$ BTBT show that the luminous efficacy changes at approximately the same rate as the LEDs using our original material, [BODFluTh $]_{2}$ FB. Another improvement that is linked to the reduced self-absorption and increased emission in the green region is the quality of the white light when the organic converters are used in a hybrid device. For (TPA-Flu) $)_{2}$ BT and (TPA-Flu) $)_{2}$ BTBT the CRI values are within a reasonable range of $(60<\mathrm{CRI}<70)$ whereas the older generation BODIPY-containing hybrid devices have poor colour rendering properties $(\ll 60)$.

\section{Conclusions}

In this work we have shown that two novel organic downconverting molecules, (TPA-Flu) $)_{2}$ BT and (TPA-Flu) ${ }_{2}$ BTBT, can produce reasonable quality white light when used in conjunction with an inorganic InGaN/GaN blue LED. These converters have improved absorption and emission properties with reduced self-absorption when compared with the BODIPY-containing 
older generation molecules, resulting in higher luminous efficacy and enhanced colour rendering properties when combined with the blue LED. The chromaticity coordinates of the converters coupled with the blue LED demonstrated white light emission. The points lay close to the Planckian locus, with CCT values from the cool to warm white regions ( $10000 \mathrm{~K}$ to $2400 \mathrm{~K}$ ) of the chromaticity diagram. The variation in concentration of the molecules varied the CCT allowing tunable white light to be easily achieved. From our investigations (TPA-Flu) $)_{2} \mathbf{B T}$ was the better performing molecule when utilised as down-converter for a white light-emitting device, both in terms of quality and efficiency. (TPA-Flu) ${ }_{2}$ BT obtained the highest CRI value of our reports to date and is considered by industry as reasonable quality white light with a CRI of 61 . The luminous efficacy was found to be more than $3 \times$ higher than both the previous generation [BODFluTh $]_{2} \mathbf{F B}$ and (TPA-Flu) ${ }_{2}$ BTBT, with an average value of $41 \mathrm{~lm} \mathrm{~W}^{-1}$. Also the highest blue-to-white efficacy value

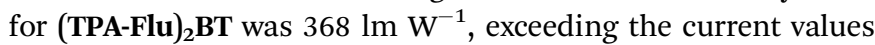
for phosphor-based LEDs.

\section{Experimental method}

\subsection{Material experimental details}

Tetrakis(triphenylphosphine)palladium $(0)\left(\mathrm{Pd}\left(\mathrm{PPh}_{3}\right)_{4}\right)$ was prepared prior to use and stored under nitrogen. Unless otherwise stated, all other reagents were sourced commercially and used without further purification. Dry solvents were obtained from a solvent purification system (SPS 400 from Innovative Technologies) using alumina as the drying agent. ${ }^{1} \mathrm{H}$ and ${ }^{13} \mathrm{C}$ nuclear magnetic resonance (NMR) spectra were recorded on either a Bruker DRX 500 apparatus at 500.13 and $125.76 \mathrm{MHz}$, or a Bruker Avance DPX400 apparatus at 400.13 and $100.6 \mathrm{MHz}$. Chemical shifts are given in ppm; all $J$ values are in $\mathrm{Hz}$. Elemental analyses were obtained on a Perkin-Elmer 2400 analyser. Matrix assisted laser desorption ionisation-time-offlight (MALDI-TOF) mass spectrometry were run on a Shimadzu Axima-CFR spectrometer (mass range 1-150 000 Da). Thermogravimetric analysis (TGA) was performed using a Perkin-Elmer Thermogravimetric Analyzer TGA7 under a constant flow of helium. Melting points were taken using a Stuart Scientific Melting Point apparatus. Absorption spectra were recorded on a Shimadzu UV 2700 instrument. Photoluminescence measurements were recorded using a Perkin-Elmer LS 50 B fluorescence spectrometer in a quartz cuvette (path length $10 \mathrm{~mm}$ ). Absolute PLQY measurements were performed in a calibrated integrating sphere attached to an Ocean Optics USB2000+ spectrometer, and a Gooch \& Housego double monochromator with a quartz halogen lamp. ${ }^{25}$ The samples were excited at $444 \mathrm{~nm}$.

\subsection{Device experimental details}

(TPA-Flu) ${ }_{2}$ BT and (TPA-Flu) $)_{2}$ BTBT were deposited on full InGaN/GaN LED structures using "GaN-on-Silicon" technology. The commercial LEDs emit around $444 \mathrm{~nm}$ which is close to the second absorption peak of both organic wavelength converters of around $430 \mathrm{~nm}$ and $443 \mathrm{~nm}$ as seen in Fig. 2. For ease of deposition and uniform coverage of the converters the LED wafer is mounted and electrically contacted within a small cup. This is the common commercial packaging of flat mount LEDs but with no encapsulation. The converters, suspended in a transparent CHDV matrix solution, are deposited over the LED wafer using a drop-cast method. The addition of a photoacid generator to the solution allows the converters to be cured under ultraviolet (UV) light $(254 \mathrm{~nm})$ to form a hard encapsulant, which also protects the LED. ${ }^{26}$ The concentration of each molecule is defined as the weight per volume $(\mathrm{w} / \mathrm{v})$ in this matrix solution. The LED cups are electrically connected in order to perform electroluminescence (EL) measurements. The EL measurements were taken by placing each LED (before and after deposition of converter) in an integrating sphere (Labsphere Illumina ${ }^{\circledR}$ plus $600 / 610,25 \mathrm{~cm}$ ) with the power to the LED driven by a Keithley source measure unit set to $25 \mathrm{~mA}$ drive current. The integrating sphere allows for full spectral characterisation of the light emission, with the software returning colorimetry values which are generated from the detected response-corrected spectrum. The integrating sphere provides absolute spectral values as all the emitted light is collected and detected with no stray light lost.

\subsection{Synthetic experimental details}

Compound 2. 4,7-Dibromo-2,1,3-benzothiadiazole (compound 1, $300 \mathrm{mg}, 1.021 \mathrm{mmol})$, reagent A (1.74 g, $3.266 \mathrm{mmol})$, $\mathrm{Pd}\left(\mathrm{PPh}_{3}\right)_{4}$ (236 mg, $0.204 \mathrm{mmol}$ ) and barium hydroxide octahydrate (1.55 g, $4.901 \mathrm{mmol})$ were charged to a reaction flask, evacuated and purged with $\operatorname{Ar}(\times 3)$. Anhydrous THF $(35 \mathrm{ml})$ and water $(3.5 \mathrm{ml})$ were added, and the mixture heated to reflux for $40 \mathrm{~h}$. After this time, the mixture was cooled to room temperature (r.t.) and diluted with water $(100 \mathrm{ml})$, then extracted with dichloromethane $(3 \times 60 \mathrm{ml})$. The combined organic fractions were washed with brine $(100 \mathrm{ml})$, then dried $\left(\mathrm{MgSO}_{4}\right)$ and concentrated under vacuum. Purification on silica gel, eluting with $10 \%$ dichloromethane in hexane afforded a yellow residue after concentration of the solvent. The residue was dissolved in the minimum volume of hot dichloromethane and precipitated with ice-cold methanol. The resulting precipitate was isolated by filtration and dried under vacuum, to afford compound 2 as a yellow-green powder (791 mg, 82\%); m.p. $164-167{ }^{\circ} \mathrm{C}$; $\delta_{\mathrm{H}}\left(\mathrm{CDCl}_{3}, 500.13 \mathrm{MHz}\right) 8.03(2 \mathrm{H}, \mathrm{dd}, J=8.0,1.5, \mathrm{ArH}), 7.97$ $(2 \mathrm{H}, \mathrm{s}, \mathrm{ArH}), 7.90-7.88$ (4H, m, ArH) $7.76(2 \mathrm{H}, \mathrm{d}, J=7.0, \mathrm{ArH})$, 7.55-7.53 (4H, m, ArH), 2.08-2.03 (8H, m, $\left.\mathrm{CH}_{2}\right), 1.17-1.10(24 \mathrm{H}$, $\mathrm{m}, \mathrm{CH}_{2}$ ), 0.85-0.80 (20H, m, $\left.\mathrm{CH}_{2}, \mathrm{CH}_{3}\right), 0.34$ (18H, s, $\mathrm{SiCH}_{3}$ ); $\delta_{\mathrm{C}}\left(\mathrm{CDCl}_{3}, 100.61 \mathrm{MHz}\right) 154.6,151.5,150.7,141.50,141.46,139.5$, 136.5, 133.8, 132.1, 128.3, 128.1, 127.9, 124.2, 120.0, 119.4, 55.3, 40.3, 31.6, 29.8, 24.0, 22.7, 14.2, -0.6; $\mathrm{m} / \mathrm{z}$ (MALDI-TOF) 945.33; elemental analysis: found C, 78.70; H, 9.08; N, 2.97; $\mathrm{C}_{62} \mathrm{H}_{84} \mathrm{~N}_{2} \mathrm{~S}_{2} \mathrm{Si}$ requires $\mathrm{C}$, 78.75; $\mathrm{H}, 8.95 ; \mathrm{N}, 2.96$.

Compound 3. Compound 2 (500 $\mathrm{mg}, 0.529 \mathrm{mmol})$ and sodium acetate $(87 \mathrm{mg}, 1.058 \mathrm{mmol})$ were charged to a reaction flask, dissolved in THF $(10 \mathrm{ml})$ and covered in foil. The reaction mixture was cooled to $0{ }^{\circ} \mathrm{C}$; and a solution of bromine $(393 \mathrm{mg}$, $2.464 \mathrm{mmol})$ in dichloromethane $(1.0 \mathrm{ml})$ added dropwise. The mixture was stirred at $0{ }^{\circ} \mathrm{C}$ and allowed to warm to r.t. 
overnight. After $24 \mathrm{~h}$, the reaction mixture was quenched with trimethylamine $(0.69 \mathrm{ml}, 4.928 \mathrm{mmol})$ and sodium sulphite (saturated aqueous solution, $80 \mathrm{ml}$ ), then extracted with dichloromethane $(4 \times 40 \mathrm{ml})$. The combined organic layers were washed with sodium bicarbonate (saturated aqueous solution, $100 \mathrm{ml})$, dried $\left(\mathrm{MgSO}_{4}\right)$ and concentrated under vacuum. Purification on silica gel, eluting with $15 \%$ dichloromethane in hexane, afforded a yellow-green residue that was dissolved in the minimum volume of hot dichloromethane and precipitated with ice-cold methanol. The product was isolated by filtration to afford compound 3 as a yellow powder $(490 \mathrm{mg}$, 90\%); m.p. $190-193{ }^{\circ} \mathrm{C} ; \delta_{\mathrm{H}}\left(\mathrm{CDCl}_{3}, 400.13 \mathrm{MHz}\right) 8.04-8.02$ (2H, m, ArH), 7.96 (2H, s, ArH), 7.89 (2H, s, ArH), $7.85(2 \mathrm{H}, \mathrm{d}$, $J=8.0 \mathrm{ArH}), 7.64(2 \mathrm{H}, \mathrm{d}, J=8.0, \mathrm{ArH}), 7.53-7.49(4 \mathrm{H}, \mathrm{m}, \mathrm{ArH})$, 2.12-1.95 (8H, m, $\mathrm{CH}_{2}$ ), 1.17-1.10 $\left(24 \mathrm{H}, \mathrm{m}, \mathrm{CH}_{2}\right), 0.88-0.75$ $\left(20 \mathrm{H}, \mathrm{m}, \mathrm{CH}_{2}, \mathrm{CH}_{3}\right) ; \delta_{\mathrm{C}}\left(\mathrm{CDCl}_{3}, 100.61 \mathrm{MHz}\right)$ 154.5, 153.8, 151.0, $140.5,139.9,136.8,133.8,130.3$, 128.6, 128.1, 126.5, 124.2, $121.5,120.0,55.8,40.4,31.7,29.9,24.0,22.8,14.2 ; \mathrm{m} / \mathrm{z}$ (MALDI-TOF) 958.70; elemental analysis: found $\mathrm{C}, 70.11 ; \mathrm{H}$, 6.92; N, 2.96; $\mathrm{C}_{56} \mathrm{H}_{66} \mathrm{Br}_{2} \mathrm{~N}_{2} \mathrm{~S}$ requires C, 70.14; H, 6.94; N, 2.92 .

(TPA-Flu) ${ }_{2}$ BT. Compound 3 (100 mg, $\left.0.104 \mathrm{mmol}\right)$, 4-(diphenylamino)phenyl boronic acid (97 $\mathrm{mg}, 0.334 \mathrm{mmol}), \mathrm{Pd}\left(\mathrm{PPh}_{3}\right)_{4}$ (24 mg, $0.021 \mathrm{mmol}$ ) and barium hydroxide octahydrate (158 $\mathrm{mg}, 0.501 \mathrm{mmol}$ ) were charged to a reaction flask, evacuated and purged with $\mathrm{Ar}(\times 3)$. Anhydrous THF $(10 \mathrm{ml})$ and water $(1.0 \mathrm{ml})$ were added, and the mixture heated to reflux for $48 \mathrm{~h}$. After this time, the mixture was cooled to r.t. and diluted with water $(100 \mathrm{ml})$, then extracted with dichloromethane $(3 \times 50 \mathrm{ml})$. The combined organic fractions were washed with brine $(100 \mathrm{ml})$, then dried $\left(\mathrm{MgSO}_{4}\right)$ and concentrated under vacuum. Purification on silica gel, eluting with $15-25 \%$ dichloromethane in hexane afforded a orange residue after concentration of the solvent. The residue was dissolved in the minimum volume of hot dichloromethane and precipitated with ice-cold methanol. The resulting precipitate was isolated by filtration and dried under vacuum, to afford compound (TPA-Flu) $)_{2} \mathbf{B T}$ as an orange powder (105 mg, 78\%); m.p. 105-108 ${ }^{\circ} \mathrm{C} ; \delta_{\mathrm{H}}\left(\mathrm{CDCl}_{3}\right.$, $400.13 \mathrm{MHz}) 8.05$ (2H, dd, $J=8.0,1.6, \operatorname{ArH}), 7.99(2 \mathrm{H}, \mathrm{s}, \operatorname{ArH})$, 7.91-7.88 (4H, m, ArH), $7.82(2 \mathrm{H}, \mathrm{d}, J=8.4 \mathrm{ArH}), 7.62-7.58$ (8H, m, ArH), 7.32-7.28 (8H, m, ArH), 7.21-7.16 (12H, m, ArH), 7.08-7.04 (4H, m, ArH), 2.16-2.02 (8H, m, $\left.\mathrm{CH}_{2}\right), 1.18-1.12(24 \mathrm{H}$, $\left.\mathrm{m}, \mathrm{CH}_{2}\right), 0.84-0.76\left(20 \mathrm{H}, \mathrm{m}, \mathrm{CH}_{2}, \mathrm{CH}_{3}\right) ; \delta_{\mathrm{C}}\left(\mathrm{CDCl}_{3}, 100.61 \mathrm{MHz}\right)$ 154.6, 152.3, 151.6, 147.9, 147.3, 141.3, 140.0, 139.8, 136.3, 135.8, 133.8, 129.51, 129.47, 128.4, 128.10, 128.05, 125.9, 124.6, 124.2, $124.1,123.2,121.3,55.5,40.6,31.7,30.0,24.1,22.8,14.2 ; \mathrm{m} / \mathrm{z}$ (MALDI-TOF) 1288.25; elemental analysis: found $\mathrm{C}, 85.45 ; \mathrm{H}$, 7.13; N, 4.25; $\mathrm{C}_{92} \mathrm{H}_{94} \mathrm{~N}_{4} \mathrm{~S}$ requires C, 85.80; H, 7.36; N, 4.35; TGA: $5 \%$ mass loss at $435{ }^{\circ} \mathrm{C}$.

Compound 5. Compound 4 (590 mg, 2.74 mmol), palladium(II) acetate $(30.8 \mathrm{mg}, 0.137 \mathrm{mmol})$, potassium carbonate (379 mg, $2.74 \mathrm{mmol}$ ) and PEG 4000 (2.743 g, $0.686 \mathrm{mmol}$ ) were dissolved in dry DMF $(10 \mathrm{ml})$ under nitrogen and the mixture was stirred at $120{ }^{\circ} \mathrm{C}$ for $20 \mathrm{~h}$. After this time water was added and the obtained solid was filtered, washed with water and dissolved in chloroform to obtain a solution. The solution was washed with brine $(3 \times 50 \mathrm{ml})$, dried over $\mathrm{MgSO}_{4}$, filtered and concentrated under reduced pressure. Purification on silica gel, eluting with 70 to $100 \%$ dichloromethane in petroleum ether afforded compound 5 as a yellow solid (298 mg, 80\%); ${ }^{1} \mathrm{H}$ NMR $\delta_{\mathrm{H}}\left(\mathrm{CDCl}_{3}, 400.13 \mathrm{MHz}\right) 8.26(1 \mathrm{H}, \mathrm{dd}, J=7.0,1.1 \mathrm{~Hz}, \operatorname{ArH})$, $8.11(1 \mathrm{H}, \mathrm{dd}, J=8.8,1.1 \mathrm{~Hz}, \mathrm{ArH}), 7.81(1 \mathrm{H}, \mathrm{dd}, J=8.8$, $7.0 \mathrm{~Hz}, \mathrm{ArH}) ; \delta_{\mathrm{C}}\left(\mathrm{CDCl}_{3}, 100.61 \mathrm{MHz}\right)$ 155.7, 153.8, 130.9, 130.2 , 129.6, 121.8; $\mathrm{m} / z$ (MALDI-TOF) 270.0; elemental analysis: found $\mathrm{C}, 53.91 ; \mathrm{H}, 2.38 ; \mathrm{N}, 20.70 ; \mathrm{C}_{12} \mathrm{H}_{6} \mathrm{~N}_{4} \mathrm{~S}_{2}$ requires $\mathrm{C}$, 53.32; $\mathrm{H}, 2.24 ; \mathrm{N}, 20.73 .^{27}$

Compound 6. Silver sulfate $(2.971 \mathrm{~g}, 9.53 \mathrm{mmol})$ was dissolved in sulfuric acid $(9 \mathrm{ml})$. Iodine $(789 \mathrm{mg}, 3.11 \mathrm{mmol})$ was added and the solution was stirred for 3 hours at r.t. until the iodine had dissolved. The mixture was then added to compound $5(280 \mathrm{mg}, 1.036 \mathrm{mmol})$ at $110{ }^{\circ} \mathrm{C}$. The resulting mixture was stirred at $110{ }^{\circ} \mathrm{C}$ for 1 hour. After this time water $(100 \mathrm{ml})$ was added, the mixture was extracted with chloroform $(4 \times 100 \mathrm{ml})$. The combined chloroform extracts were filtrated in a glass fritted funnel and the solution was concentrated under reduced pressure to afford a yellow solid that was recrystallized from boiling toluene to afford compound 6 as a yellow powder $(244 \mathrm{mg}, 45 \%) ; \delta_{\mathrm{H}}$ $\left(\mathrm{CDCl}_{3}, 400.13 \mathrm{MHz}\right) 8.30(2 \mathrm{H}, \mathrm{d}, J=7.5 \mathrm{~Hz}, \mathrm{ArH}), 8.06(2 \mathrm{H}, \mathrm{d}$, $J=7.5 \mathrm{~Hz}, \mathrm{ArH}$ ); $m / z$ (MALDI-TOF) 522.4. ${ }^{27}$ Compound 6 was used in the next synthetic step without further purification or analysis.

Compound 7. Compound $6(240 \mathrm{mg}, 0.409 \mathrm{mmol})$ and potassium carbonate (226 $\mathrm{mg}, 1.636 \mathrm{mmol}$ ) were dissolved in toluene $(10 \mathrm{ml})$ under argon. (9,9-Dihexyl-7-(trimethylsilyl)-9Hfluoren-2-yl)boronic acid (reagent $\mathrm{A}, 700 \mathrm{mg}, 1.555 \mathrm{mmol}$ ) in toluene $(10 \mathrm{ml})$ and tetrakis(triphenylphosphine)palladium(0) (95 mg, $0.082 \mathrm{mmol}$ ) were added, and the mixture was heated at reflux for $70 \mathrm{~h}$. After this time brine $(50 \mathrm{ml})$ was added and the mixture was extracted with dichloromethane $(3 \times 50 \mathrm{ml})$. The combined organic layers were washed with brine $(2 \times 50 \mathrm{ml})$, water $(2 \times 50 \mathrm{ml})$, died over $\mathrm{MgSO}_{4}$, filtered and concentrated under reduced pressure. Purification on silica gel, eluting with $20 \%$ dichloromethane in hexane afforded a yellow solid that was recrystallised from hot ethanol to afford compound 7 as a yellow powder $(274 \mathrm{mg}, 62 \%)$; m.p. $218-220{ }^{\circ} \mathrm{C} ; \delta_{\mathrm{H}}\left(\mathrm{CDCl}_{3}\right.$, $400.13 \mathrm{MHz}) 8.49(2 \mathrm{H}, \mathrm{d}, J=7.4 \mathrm{~Hz}, \operatorname{ArH}), 8.06$ (2H, dd, $J=7.9,1.6 \mathrm{~Hz}, \operatorname{ArH}), 8.03-7.97(4 \mathrm{H}, \mathrm{m}, \operatorname{ArH}), 7.90(2 \mathrm{H}, \mathrm{d}$, $J=7.9 \mathrm{~Hz}, \mathrm{ArH}), 7.77(2 \mathrm{H}, \mathrm{dd}, J=7.3,0.9 \mathrm{~Hz}, \mathrm{ArH}), 7.53(4 \mathrm{H}, \mathrm{dd}$, $J=8.6,1.1 \mathrm{~Hz}, \mathrm{ArH}), 2.04\left(8 \mathrm{H}, \mathrm{dq}, J=12.9,7.4,6.5 \mathrm{~Hz}, \mathrm{CH}_{2}\right)$, 1.19-1.05 (24H, m, CH $)$, 0.88-0.73 (20H, m, $\left.\mathrm{CH}_{3}\right), 0.34(18 \mathrm{H}, \mathrm{s}$, $\left.\mathrm{SiCH}_{3}\right) ; \delta_{\mathrm{C}}\left(\mathrm{CDCl}_{3}, 100.61 \mathrm{MHz}\right) 154.6,154.4,151.5,150.7$, $141.7,141.4,139.6,136.3,135.1,132.1,131.4,128.7,128.4$, 127.9, 127.8, 124.3, 120.0, 119.4, 76.8, 55.3, 40.2, 31.6, 29.8, 24.0, 22.7, $-0.7 ; \mathrm{m} / \mathrm{z}$ (MALDI-TOF) 1079.3; elemental analysis: found $\mathrm{C}, 75.43 ; \mathrm{H}, 7.80 ; \mathrm{N}, 5.27 ; \mathrm{C}_{68} \mathrm{H}_{86} \mathrm{~N}_{4} \mathrm{~S}_{2} \mathrm{Si}_{2}$ requires $\mathrm{C}$, 75.64; H, 8.03; N, 5.19.

Compound 8. Compound $7(0.220 \mathrm{~g}, 0.204 \mathrm{mmol})$ and sodium acetate $(0.033 \mathrm{~g}, 0.408 \mathrm{mmol})$ were dissolved in dry THF $(30 \mathrm{ml})$ under argon. The mixture was cooled to $0{ }^{\circ} \mathrm{C}$, dibromine (2 $\mathrm{M}$ solution in dichloromethane, $0.48 \mathrm{ml}$, $0.949 \mathrm{mmol}$ ) was added dropwise and the mixture was stirred for $20 \mathrm{~h}$ at room temperature. After this time, triethylamine $(0.23 \mathrm{ml}, 1.630 \mathrm{mmol})$ was added and the mixture stirred for 30 minutes. Sodium sulfate ( $100 \mathrm{ml}$, saturated aqueous solution) 
was added and the mixture was extracted with dichloromethane $(3 \times 50 \mathrm{ml})$. The combined organic layers were washed with water $(3 \times 50 \mathrm{ml})$, dried over $\mathrm{MgSO}_{4}$, filtrate and concentrated under reduced pressure. The orange solid obtained was filtered through a silica gel plug eluting with dichloromethane and then concentrated under reduced pressure to afford a solid that was dissolved in the minimum volume of boiling dichloromethane. Cold methanol was added and compound 8 was reprecipitated as an orange powder (201 $\mathrm{mg}$, 90\% yield); m.p. $166-168{ }^{\circ} \mathrm{C} ; \delta_{\mathrm{H}}\left(\mathrm{CDCl}_{3}, 400.13 \mathrm{MHz}\right) 8.49(2 \mathrm{H}, \mathrm{d}, J=$ $7.4 \mathrm{~Hz}, \mathrm{ArH}), 8.07$ (2H, dd, $J=7.8,1.5 \mathrm{~Hz}, \mathrm{ArH}), 8.03-7.97$ $(4 \mathrm{H}, \mathrm{m}, \mathrm{ArH}), 7.86(2 \mathrm{H}, \mathrm{d}, J=7.9 \mathrm{~Hz}, \operatorname{ArH}), 7.64(2 \mathrm{H}, \mathrm{d}, J=$ $7.9 \mathrm{~Hz}, \mathrm{ArH}), 7.56-7.46$ (4H, m, ArH), 2.13-1.93 (8H, m, $\left.\mathrm{CH}_{2}\right)$, 1.19-1.07 (24H, m, CH$), 0.84-0.72\left(20 \mathrm{H}, \mathrm{m}, \mathrm{CH}_{3}\right) ; \delta_{\mathrm{C}}\left(\mathrm{CDCl}_{3}\right.$, 100.61 MHz) 154.6, 154.3, 153.7, 150.9, 140.6, 136.6, 134.9, 131.3, 130.2, 128.8, 128.6, 127.9, 126.4, 124.2, 121.6, 121.5, 120.0, 55.7, 40.4, 31.6, 29.8, 24.0, 22.7, 14.2; $\mathrm{m} / z$ (MALDI-TOF) 1091.9; elemental analysis: found $\mathrm{C}, 68.36 ; \mathrm{H}, 6.13 ; \mathrm{N}, 5.15 ; \mathrm{C}_{62} \mathrm{H}_{68} \mathrm{Br}_{2} \mathrm{~N}_{4} \mathrm{~S}_{2}$ requires $\mathrm{C}$, 68.12; H, 6.27; N, 5.13.

(TPA-Flu) $)_{2}$ BTBT. Compound 8 (84 mg, $\left.0.077 \mathrm{mmol}\right)$, (4-(diphenylamino)phenyl)boronic acid (67 $\mathrm{mg}, 0.231 \mathrm{mmol}$ ), tetrakis(triphenylphosphine)palladium(0) (18 mg, $0.015 \mathrm{mmol}$ ), barium hydroxide octahydrate $(49 \mathrm{mg}, 0.154 \mathrm{mmol})$ and tetrabutylammonium bromide $(25 \mathrm{mg}, 0.077 \mathrm{mmol}$ ) were dissolved in a THF ( $9 \mathrm{ml})$ and degassed water $(2 \mathrm{ml})$ and the mixture was heated at reflux for 44 hours. After this time brine $(50 \mathrm{ml})$ was added and the mixture was extracted with dichloromethane $(3 \times 50 \mathrm{ml})$. The combined organic layers were washed with water $(3 \times 50 \mathrm{ml})$, dried over $\mathrm{MgSO}_{4}$, filtered and concentrated under reduced pressure. A first purification on silica gel, eluting with $50 \%$ dichloromethane in hexane afforded an orange residue. A second purification on silica gel, first eluting with $25 \%$ dichloromethane in hexane to remove by-products and then $33 \%$ dichloromethane in hexane afforded TPA-Flu-BTBT-Flu-TPA as an orange powder (70 mg, 64\%); m.p. $124-126{ }^{\circ} \mathrm{C} \delta_{\mathrm{H}}\left(\mathrm{CDCl}_{3}\right.$, $400.13 \mathrm{MHz}) 8.51(2 \mathrm{H}, \mathrm{d}, J=7.4 \mathrm{~Hz}, \operatorname{ArH}), 8.10$ (2H, dd, $J=7.8,1.6 \mathrm{~Hz}, \operatorname{ArH}), 8.05-8.00(4 \mathrm{H}, \mathrm{m}, \operatorname{ArH}), 7.91(2 \mathrm{H}, \mathrm{d}$, $J=7.9 \mathrm{~Hz}, \mathrm{ArH}), 7.83(2 \mathrm{H}, \mathrm{d}, J=8.4 \mathrm{~Hz}, \mathrm{ArH}), 7.63-7.57(8 \mathrm{H}, \mathrm{m}$, ArH), 7.33-7.27 (8H, m, ArH), 7.22-7.15 (12H, m, ArH), 7.09-7.03 (4H, m, ArH), 2.20-2.01 (8H, m, $\left.\mathrm{CH}_{2}\right), 1.19-1.09$ $\left(24 \mathrm{H}, \mathrm{m}, \mathrm{CH}_{2}\right), 0.91-0.82\left(8 \mathrm{H}, \mathrm{m}, \mathrm{CH}_{2}\right), 0.79(12 \mathrm{H}, \mathrm{t}, J=$ $\left.6.9 \mathrm{~Hz}, \mathrm{CH}_{3}\right) ; \delta_{\mathrm{C}}\left(\mathrm{CDCl}_{3}, 100.61 \mathrm{MHz}\right) 151.5,147.8,141.5$, $140.0,139.6,136.0,135.7,135.1,131.4,129.4,128.7,128.5$, $128.0,127.8,125.8,124.5,124.2,124.2,123.1,121.2,120.4$, 119.9, 55.5, 40.6, 31.7, 29.9, 24.1, 22.8, 14.2; $\mathrm{m} / \mathrm{z}$ (MALDI-TOF) 1421.2; elemental analysis: found $\mathrm{C}, 83.10 ; \mathrm{H}, 6.82 ; \mathrm{N}, 5.83$; $\mathrm{C}_{98} \mathrm{H}_{96} \mathrm{~N}_{6} \mathrm{~S}_{2}$ requires C, 82.78; $\mathrm{H}, 6.81 ; \mathrm{N}, 5.91$; TGA: $5 \%$ mass loss at $418{ }^{\circ} \mathrm{C}$.

\section{Acknowledgements}

The authors would like to thank UK EPSRC (Grant No. EP/I012591/1 "Lighting the Future" and EP/L016982/1 "Next generation white LEDs using hybrid inorganic/organic semiconductor nanostructures for general illumination and wireless communication") for financial support. DJW received funding through EPSRC's Manufacturing Fellowship in Gallium Nitride (EP/N01202X/1). PJS thanks the Royal Society for a Wolfson Research Merit Award. The data associated with this research are available at http://dx.doi.org/10.15129/b3c341df-24e5-406ba1f2-970cb27e7e18 or from the corresponding author.

\section{References}

1 C. J. Humphreys, MRS Bull., 2008, 33, 459.

2 J. Y. Tsao, M. H. Crawford, M. E. Coltrin, A. J. Fischer, D. D. Koleske, G. S. Subramania, G. T. Wang, J. J. Wierer and R. F. Karlicek, Adv. Opt. Mater., 2014, 2, 809.

3 P. Schlotter, R. Schmidt and J. Schneider, Appl. Phys. A: Mater. Sci. Process., 1997, 64, 417.

4 F. Hide, P. Kozodoy, S. P. DenBaars and A. J. Heeger, Appl. Phys. Lett., 1997, 70, 2664.

5 C. Zhang and A. J. Heeger, J. Appl. Phys., 1998, 84, 1579.

6 "Nobel Prize in Physics 2014", http://www.nobelprize.org/ nobelprizes/physics/laureates/2014/, (url date: 21/03/2016).

7 R. W. Martin, P. R. Edwards, R. Pecharroman-Gallego, C. Liu, C. J. Deatcher, I. M. Watson and K. P. O'Donnell, J. Phys. D: Appl. Phys., 2002, 35, 604.

8 G. Heliotis, P. N. Stavrinou, D. D. C. Bradley, E. Gu, C. Griffin, C. W. Jeon and M. D. Dawson, Appl. Phys. Lett., 2005, 87, 103505.

9 E. Gu, H. X. Zhang, H. D. Sun, M. D. Dawson, A. R. Mackintosh, A. J. C. Kuehne, R. A. Pethrick, C. Belton and D. D. C. Bradley, Appl. Phys. Lett., 2007, 90, 031116.

10 V. M. Agranovich, Y. N. Gartstein and M. Litinskaya, Chem. Rev., 2011, 111, 5179.

11 Z. Yue, Y. F. Cheung, H. W. Choi, Z. Zhao, B. Z. Tang and K. S. Wong, Opt. Mater. Express, 2013, 3, 1906.

12 M. T. Sajjad, P. P. Manousiadis, H. Chun, D. A. Vithanage, S. Rajbhandari, A. L. Kanibolotsky, G. Faulkner, D. O’Brien, P. J. Skabara, I. D. W. Samuel and G. A. Turnbull, ACS Photonics, 2015, 2, 194.

13 N. Laurand, B. Guilhabert, J. McKendry, A. E. Kelly, B. Rae, D. Massoubre, Z. Gong, E. Gu, R. Henderson and M. D. Dawson, Opt. Mater. Express, 2012, 2, 250.

14 H. Chun, C.-J. Chiang, A. Monkman and D. O'Brien, J. Lightwave Technol., 2013, 31, 3511.

15 N. J. Findlay, C. Orofino-Peña, J. Bruckbauer, S. E. T. Elmasly, S. Arumugam, A. R. Inigo, A. L. Kanibolotsky, R. W. Martin and P. J. Skabara, J. Mater. Chem. C, 2013, 1, 2249.

16 N. J. Findlay, J. Bruckbauer, A. R. Inigo, B. Breig, S. Arumugam, D. J. Wallis, R. W. Martin and P. J. Skabara, Adv. Mater., 2014, 26, 7290.

17 J. Bruckbauer, C. Brasser, N. J. Findlay, P. R. Edwards, D. J. Wallis, P. J. Skabara and R. W. Martin, J. Phys. D: Appl. Phys., 2016, 49, 405103.

18 T. W. Murphy, J. Appl. Phys., 2012, 111, 104909.

19 E. Taylor, P. R. Edwards and R. W. Martin, Phys. Status Solidi A, 2012, 209, 461. 
20 W. Davis and Y. Ohno, J. Mod. Opt., 2009, 56, 1412.

21 W. Davis and Y. Ohno, Opt. Eng., 2010, 49, 033602.

22 N. Bardsley, S. Bland, M. Hansen, L. Pattison, M. Pattison, K. Stober and M. Yamada, Energy Efficiency \& Renewable Energy, U.S. Department of Energy, 2015.

23 A. N. S. I. (ANSI), NEMA, 2008.

24 Y. Ohno, Leukos, 2014, 10, 47.
25 J. C. de Mello, H. F. Wittmann and R. H. Friend, Adv. Mater., 1997, 9, 230.

26 A. J. C. Kuehne, D. Elfström, A. R. Mackintosh, A. L. Kanibolotsky, B. Guilhabert, E. Gu, I. F. Perepichka, P. J. Skabara, M. D. Dawson and R. A. Pethrick, Adv. Mater., 2009, 21, 781.

27 J. C. Bijleveld, M. Shahid, J. Gilot, M. M. Wienk and R. A. J. Janssen, Adv. Funct. Mater., 2009, 19, 3262. 